\title{
Diagnosing the rare: a neglected problem?
}

How would you react - after initial exasperation - to a recent newspaper report of a Lincolnshire woman whose actinomycosis was only diagnosed after 20 years and, allegedly, 1000 consultations? ${ }^{1}$ I felt a mixture of admiration for her new GP, said to have helped to make the diagnosis, and dismay. How on earth are GPs supposed to diagnose such rare conditions? How should we cope with missing rare diagnoses, and the fear of missing them? Could we be better prepared for dealing with the rare?

Medical students traditionally overemphasise the rare, and the adage 'Common things occur commonly' remains a useful corrective to false perceptions of disease incidence. However, we can become so used to dealing with the common that we risk neglecting the rare. Or rather, some of us do: we vary in our interest in the rare and ways of coping with it. As a novice GP I sometimes asked an older partner for diagnostic advice. He always thought of worrying rarities but patients never turned out to have them, so I stopped asking for his advice. I later realised his approach was wiser than mine. Subconscious denial of the possibility of meeting very rare conditions makes it easier to cope with the fear of missing them, but doesn't help diagnose them. Kawasaki's disease was one of my lurking, half-suppressed fears, but luckily I never knowingly met it in over 30 years as a GP.

Missing a rare disease feels much less culpable than missing a common one but it is still distressing for both patient and doctor. I don't know whether a faulty mindset or lack of knowledge is the most common cause. My knowledge was certainly at fault when I missed acute epiglottitis in an adult, because I associated it only with stridor in young children. More positively, knowledge of rare causes of hypertension - imprinted remarkably effectively by having to give a presentation at a surgical unit meeting as a student - helped me diagnose a phaeochromocytoma almost 40 years later. Luck was another big factor, naturally. Rare conditions can clearly be a source of considerable interest and satisfaction as well as pain, and they don't have to be serious or difficult to diagnose to be memorable: I once saw 4year-old twins, each with a fluorescent plastic bead stuck down his left ear.

Discussing rarity is not helped by the lack of agreed terms. One European definition of rare diseases are those that affect less than 1 in 2000 citizens. $^{2}$ Grouped together, they are common in general practice, with a combined prevalence of $6-8 \% .^{2}$ However, it's the incidence of individual diseases that matters for diagnosis. Wikipedia defines rare diseases pragmatically as ones that a busy GP would not expect to see more than once a year, but the real challenge is those we can expect only once in a lifetime, or less. A GP in the UK has about a 1 in 2 chance of seeing acute adult epiglottitis in a 35-year career, 1 in 4 of Kawasaki's disease, and probably considerably less of phaeochromocytoma. As for conditions with only a few cases reported, perhaps all we can do is keep in the back of our mind that once or twice in our careers we just might meet something extremely rare. They do at least help remind us what an extraordinary and fascinating occupation medicine is.

The crucial problem in diagnosing the rare is striking the right balance between, on the one hand, seeing it in everything with consequent over-investigation and needless anxiety for patients - and on the other, assuming we will never see it with consequent missed diagnoses. Teaching and learning about this subject seems neglected: I can find no reference to it in the College's curriculum for GP training, ${ }^{3}$ and when did you last come across a CPD course on it? Does this reflect more general undervaluing of the GP's role as diagnostician in these days of preventive medicine and QOF targets?
That patient with actinomycosis might not be too happy to know that the description of 'the exemplary GP' in Good Medical Practice for General Practitioners ${ }^{4}$ makes no direct mention of diagnostic acumen.

\section{John Temple}

\section{REFERENCES}

1. The Daily Mail. Woman who visited doctor 1,000 times over 20 years is finally told what's wrong with her - and it's incurable. 24 October 2008. http://www.dailymail.co.uk/health/article1080293/Woman-visited-doctors-1-000-times-20years-finally-told-whats-wrong-incurable.html(accessed 12 Nov 2008)

2. European Organisation for Rare Diseases. Rare Diseases: Understanding this Public Health Priority. Paris: EURORDIS, 2005.

http://www.eurordis.org/IMG/pdf/princeps_docume nt-EN.pdf (accessed 13 Nov 2008).

3. Royal College of General Practitioners. GP Curriculum statements. London: RCGP, 2007. http://www.rcgpcurriculum.org.uk/curriculum_documents/gp_curric ulum_statements.aspx (accessed 13 Nov 2008).

4. Royal College of General Practitioners. Good medical practice for general practitioners. London: RCGP, 2007. http://www.rcgp.org.uk/PDF/Good\%20Medical\%20P ractice $\% 20$ for $\% 20$ General $\% 20$ Practitioners $\% 20 \% 5 \mathrm{~B}$ 2008\%5D.pdf (accessed 28 Nov 2008).

DOI: 10.3399/bjgp09X394914 